\title{
Soluble Colloidal Manganese Dioxide: Formation, Characterization and Application in Oxidative Kinetic Study of Ciprofloxacin
}

\author{
Gajala Tazwar, Vijay Devra* \\ Department of Chemistry, Janki Devi Bajaj Government Girls College, \\ Kota, Rajasthan (324001), India.
}

Received: 18th July 2019; Revised: 27th August 2019; Accepted: $13^{\text {th }}$ September 2019; Available online: $28^{\text {th }}$ February 2020; Published regularly: April 2020

\begin{abstract}
Soluble colloidal manganese dioxide was formed by reduction of potassium permanganate with sodium thiosulphate in neutral aqueous medium at $25{ }^{\circ} \mathrm{C}$. The obtained nano-sized colloidal manganese dioxide was found to be dark reddish-brown in color and stable for several months. The formation of manganese dioxide was confirmed by UV-visible spectrophotometer and determination of oxidation state of Mn species in manganese dioxide. The effect of different concentration of sodium thiosulphate on the formation of manganese dioxide was also studied. The nano-sized colloid manganese dioxide was characterized by transmission electron microscopy and Fourier transform infrared spectrophotometer. The formed soluble colloidal manganese dioxide was used as an oxidant in oxidation of ciprofloxacin in perchloric acid medium at $35{ }^{\circ} \mathrm{C}$. The reaction was first-order concerning to concentration of manganese dioxide and hydrogen ion but fractional order with ciprofloxacin. The results suggest formation of complex between ciprofloxacin and manganese dioxide. The oxidation products were also identified based on stoichiometric and characterization results. Copyright (C) 2020 BCREC Group. All rights reserved
\end{abstract}

Keywords: Soluble colloidal manganese dioxide; Ciprofloxacin; Characterization; Kinetics; Oxidation

How to Cite: Tazwar, G., Devra, V. (2020). Soluble Colloidal Manganese Dioxide: Formation, Characterization and Application in Oxidative Kinetic Study of Ciprofloxacin. Bulletin of Chemical Reaction Engineering \& Catalysis, 15(1), 74-83 (doi:10.9767/bcrec.15.1.5436.74-83)

Permalink/DOI: https://doi.org/10.9767/bcrec.15.1.5436.74-83

\section{Introduction}

Manganese dioxide $\left(\mathrm{MnO}_{2}\right)$ is one of the most important oxidizing agent for both organic and inorganic compounds $[1,2]$ with an oxidation potential of $1.23 \mathrm{~V}$ [3]. Due to its importance such as the low toxicity, low cost, electrochemical behavior, environmental compatibility and ease of handling, many researchers have been developed different methods for preparation of soluble colloidal $\mathrm{MnO}_{2}$ [4-6]. Soluble colloidal $\mathrm{MnO}_{2}$ is generally formed by the reduction of $\mathrm{MnO}_{4}$ -

* Corresponding Author.

E-mail: v_devra1@rediffmail.com (V. Devra);

Mobile No. 91-9352602303 ion in aqueous solution with many reductants including $\mathrm{Mn}^{2+}$ ion [7]. Perez-Benito et al. [8-10] have also been reported as a method for preparation of perfectly transparent dark brown water-soluble colloidal manganese dioxide sols by the permanganate-thiosulphate reaction in aqueous neutral conditions. The formed soluble colloidal $\mathrm{MnO}_{2}$ has been characterized by different instrumental techniques and determined by iodometric method [11-13]. The existence of manganese(IV) in the aqueous solution in colloidal form and as negatively charged species has been reported in the literature [14-16], and the oxidizing ability is limited under ordinary conditions due to its insolubility [17]. In fact, manganese oxides have been shown to be capable of ox- 
idizing a wide range of organic contaminants [18-21]. It has reactive surfaces that play important role in transformation of organic pollutants such as synthetic hormones, antiinflammatory drugs, antibacterial agents, bisphenol A, phenols, sulfides, 2-mercaptobenzothiazole (2MBT), and sulfadiazine in soil and aquatic environment [22,23]. The kinetics and mechanism of oxidation of simple organic reactants like lactic acid, aspartic acid, oxalic acid, mandelic acid, amino acid, D-fructose, D-glucose, Cysteine and glutathione [12,24-29], etc. by colloidal $\mathrm{MnO}_{2}$ have been studied.

Ciprofloxacin (CIP) \{1-cyclopropyl-6-fluoro1,4-dihydro-4-oxo-7-(piperazine-1-yl)-quinolone3 -carboxylic acid\}, a common fluoroquinolone is a primary degradation product of enrofloxacin. It is a second-generation fluoroquinolone antimicrobial agent and possesses two relevant ionizable functional groups: a basic piperazinyl group and a carboxylic group which is required for antimicrobial activity. Because of their continued use, the environment impact of such antibacterial agents is of serious concern for public health, so for requires development of the various oxidation process for the transformation and degradation of fluoroquinolones in water. The literature survey reveals that the oxidation of CIP by many oxidants, such as: hexacyanoferrate(III), chloramine- $\mathrm{B}, \mathrm{Cl}_{2}, \mathrm{ClO}_{2}$, $\mathrm{CeSO}_{4}$, and $\mathrm{Fe}(\mathrm{VI})$ [30-34], have been carried out in either alkaline or acidic medium. Studies reveal that the piperazine moiety of CIP is the predominant oxidative site for oxidation [35-39] Literature survey confessed that the kinetics and mechanism of degradation of some antibiotics by colloidal $\mathrm{MnO}_{2}$ in aqueous acidic/alkaline medium have been studied earlier [40-42]. Yuan-Li et al [43] reported that transformation pathway of levofloxacin in the manganese oxide system involving oxidation and dealkylation while the antibacterial activity was not markedly affected by addition of $\mathrm{MnO}_{2}$. Zhang \& Haung [44] also reports the antibacterial agents are highly susceptible to metal oxide- facilitated oxidation and exhibit complex reaction kinetics, which are affected by reaction conditions. However, the details of CIP oxidation by colloidal $\mathrm{MnO}_{2}$ in an aqueous acidic medium are yet unknown. Therefore, the aim of this paper is the formation of colloidal $\mathrm{MnO}_{2}$, characterized them by different instrumental techniques and its application in the oxidation of CIP in aqueous acidic medium with kinetic and mechanistic aspects.

\section{Materials and Method}

\subsection{Materials}

Ciprofloxacin hydrochloride was purchased from KORES India Limited, Mumbai, was used in the experiment. A solution was always freshly prepared by dissolving a known amount of the CIP in double-distilled water. To maintain the acidity and ionic strength of the reaction perchloric acid (MERCK) and sodium perchlorate (MERCK) were used, respectively. Other reagents employed in this study were either of AnalaR or guaranteed reagent grade and were used as received. Doubly distilled water was employed throughout the study; second distillation was from alkaline potassium permanganate solution in an all glass assembly.

\subsection{Formation of $\mathrm{MnO}_{2}$}

For the formation of water-soluble colloidal $\mathrm{MnO}_{2}$, required volume of $\mathrm{Na}_{2} \mathrm{~S}_{2} \mathrm{O}_{3}$ solution (20 $\left.\mathrm{cm}^{3}, 2.0 \times 10^{-2} \mathrm{~mol}_{\mathrm{dm}}{ }^{-3}\right)$ was added to a standard solution of $\mathrm{KMnO}_{4}\left(10 \mathrm{~cm}^{3}, 0.1 \mathrm{~mol}^{-\mathrm{dm}^{-3}}\right)$ and reaction mixture was diluted with required volume of water in $2 \mathrm{dm}^{-3}$ standard flask [10] The resulting solution was dark brown and perfectly transparent and stable for several weeks. The absorption spectrum of the reaction mixture consists of one broadband covering the whole visible region of the spectrum with $\lambda_{\max }$ $390 \mathrm{~nm}$. The studies were performed at different concentration of $\mathrm{Na}_{2} \mathrm{~S}_{2} \mathrm{O}_{3}$ to investigate formation and particle size of colloidal $\mathrm{MnO}_{2}$.

\subsection{Characterizations}

For the preliminary characterization of formed colloidal $\mathrm{MnO}_{2}$ and kinetic measurements, a Peltier accessory (temperatureControlled) attached to a double beam, the UVVisible spectrophotometer (U.V.3000 ${ }^{+} \mathrm{LABIN}$ DIA, Mumbai) with U.V. path length $1.0 \mathrm{~cm}$ in the spectral range $200-800 \mathrm{~nm}$, was used. Transmission Electron Microscopy (TEM) was used to study the morphology of colloidal $\mathrm{MnO}_{2}$. Samples for TEM analysis were prepared by drop-coating $\mathrm{MnO}_{2}$ suspension onto carbon-coated copper grid. The film on the TEM grid was allowed to stand for 2 minutes, following then the extra solution was removed using a blotting paper and the grid allowed drying before measurement on TEM (ModelTecnai G2 20 (FEI) S-Twin) instrument. Additionally, the presence of metal in the sample was analyzed by energy-dispersive X-ray (EDX) spectrometer. Stability and an average size of colloidal $\mathrm{MnO}_{2}$ have been investigated by zeta sizer and zeta potential (Zetasizer ver. 
7.11, Malvern). The spectrum of colloidal $\mathrm{MnO}_{2}$ and oxidation product were recorded from Fourier Transform Infrared (FT-IR) Spectrophotometer (ALPHA-T, Bruker, Germany) in the range of $400-4000 \mathrm{~cm}^{-1}$ by mixing sample with dried $\mathrm{KBr}$ (in 1:20 weight ratio) with a resolution of $4 \mathrm{~cm}^{-1}$. Liquid Chromatography Mass Spectroscopy (LC-MS), (Q-TOF Micromass, WATERS Company, UK), was used for oxidation product analysis over a mass scan range of $50-1000 \mathrm{~m} / \mathrm{z}$.

\subsection{Kinetic Measurements}

In all the kinetic runs, the oxidation of CIP by colloidal $\mathrm{MnO}_{2}$ was carried out under pseudo first-order condition. The required concentrations of reactants (CIP, $\mathrm{HClO}_{4}$, and $\mathrm{NaClO}_{4}$ ) were taken in the glass stopper Erlenmeyer flask and the reaction was initiated by addition of required concentration of colloidal $\mathrm{MnO}_{2}$ at

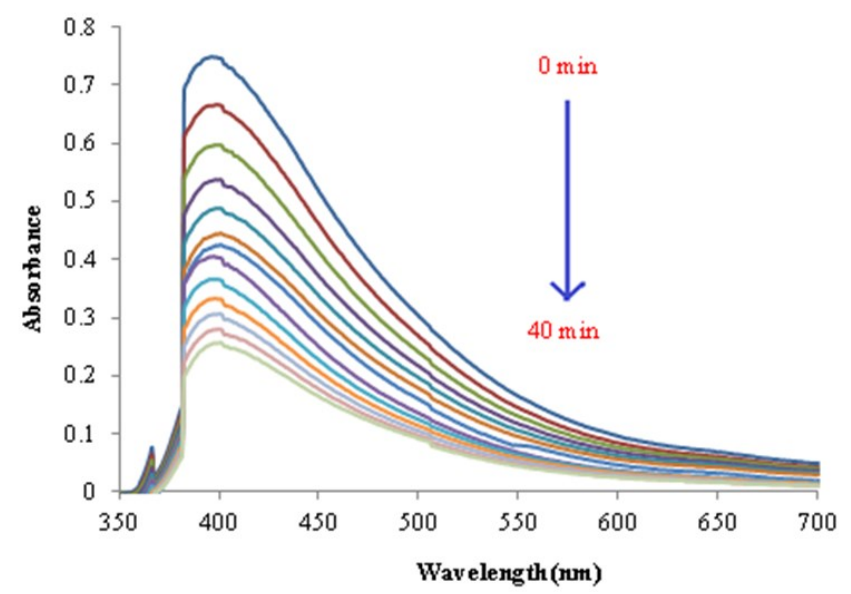

Figure 1. UV-visible absorption spectra of absorbance versus wavelength during the oxidation of ciprofloxacin by colloidal $\mathrm{MnO}_{2}$ in acidic medium at $35{ }^{\circ} \mathrm{C} .\left[\mathrm{MnO}_{2}\right]=5.0 \times 10^{-5},[\mathrm{CIP}]=2.0 \times 10^{-4},\left[\mathrm{H}^{+}\right]=$ $2.0 \times 10^{-4}$ and $\mathrm{I}=4.0 \times 10^{-4} / \mathrm{mol}^{-\mathrm{dm}^{-3}}$.

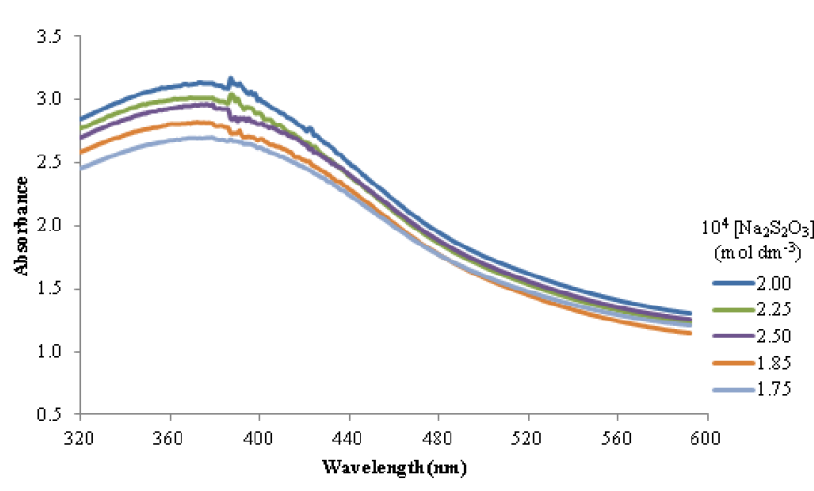

Figure 2. UV-visible absorption spectra of absorbance versus wave length of the mixtures containing a fixed amount of $\mathrm{KMnO}_{4}\left(2.0 \times 10^{-4} \mathrm{~mol}^{\left.-\mathrm{dm}^{-3}\right)}\right.$ and varying amounts of $\mathrm{Na}_{2} \mathrm{~S}_{2} \mathrm{O}_{3}$ at $35^{\circ} \mathrm{C}$.
$35{ }^{\circ} \mathrm{C}$. The progress of the reaction was followed by monitoring absorbance of $\mathrm{MnO}_{2}$ at $390 \mathrm{~nm}$ in UV-Visible spectrophotometer at different time intervals (Figure 1). All the kinetics runs were followed up to $80 \%$ completion of the reaction. The pseudo first-order rate constants $\left(k_{o b s}\right)$ were evaluated from plots of log (absorbance) versus time.

\section{Results and Discussion}

\subsection{Characterization of $\mathrm{MnO}_{2}$}

Formation of colloidal $\mathrm{MnO}_{2}$ by reduction of permanganate ions by sodium thiosulfate was studied by UV-Vis spectroscopy. The effect of different concentrations of sodium thiosulfate on the formation and particle size of nanoparticles were also investigated (Figure 2). At lower $\left[\mathrm{Na}_{2} \mathrm{~S}_{2} \mathrm{O}_{3}\right]\left(1.75 \times 10^{-4}\right.$ mol.dm $\left.{ }^{-3}\right)$, a weak absorption band at $390 \mathrm{~nm}$ was observed, indicating that due to insufficient reduction relatively low concentration of $\mathrm{MnO}_{2}$ was produced. As the $\left[\mathrm{Na}_{2} \mathrm{~S}_{2} \mathrm{O}_{3}\right]$ increases up to $2.0 \times 10^{-4}$ mol.dm ${ }^{-3}$, the intensity of absorption band at $390 \mathrm{~nm}$ increases after that absorption band becomes lower, indicating precipitation of colloidal $\mathrm{MnO}_{2}$ at higher $\left[\mathrm{Na}_{2} \mathrm{~S}_{2} \mathrm{O}_{3}\right]$. However, maximum absorption band was obtained at $2.0 \times 10^{-4} \mathrm{~mol} \mathrm{dm}^{-3}$, suggesting optimum concentration of $\mathrm{Na}_{2} \mathrm{~S}_{2} \mathrm{O}_{3}$ for the formation of colloidal $\mathrm{MnO}_{2}$. The resulting solution was dark reddish-brown and perfectly transparent and stable for several weeks.

The energy dispersive spectrometer spectrum indicates the $\mathrm{Mn}$ and $\mathrm{O}$ elements present in synthesized sample confirming the formation of colloidal nano-sized $\mathrm{MnO}_{2}$ (Figure 3). TEM analysis was carried out to determine size and shape of colloidal $\mathrm{MnO}_{2}$; the images show that the formed particles were needle shape (Figure 4(a)) with average size $20.59 \mathrm{~nm}$

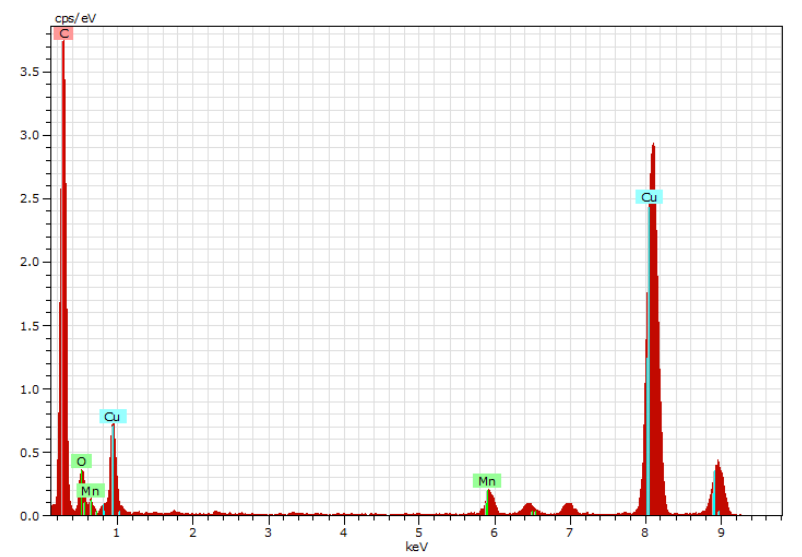

Figure 3. EDX analysis of synthesized colloidal $\mathrm{MnO}_{2}$. 
at $\left[\mathrm{Na}_{2} \mathrm{~S}_{2} \mathrm{O}_{3}\right]=2.0 \times 10^{-4}$ mol.dm ${ }^{-3}$. Whereas, at higher $\left[\mathrm{Na}_{2} \mathrm{~S}_{2} \mathrm{O}_{3}\right]$, TEM results (Figure $4(\mathrm{~b})$ ), suggesting that too many reducing agent cause aggregation of formed particle. It is possible due to the interaction between capping molecules bound to the surface of particles and secondary reduction process on surface of performed nuclei [36]. The results are well consistent with U.V. spectra in Figure 3. The selected area electron diffraction (SAED) pattern (Figure 4(b) inset) recorded colloidal $\mathrm{MnO}_{2}$. The ring-like diffraction indicates that the particles are crystalline [11]. Zeta sizer (dynamic light scattering) and zeta potential have been suggested to play an important role in the size distribution and stability of synthesized soluble colloidal $\mathrm{MnO}_{2}$, respectively. The zeta potential of colloidal $\mathrm{MnO}_{2}$ was found to be $-41.1 \mathrm{mV}$ with average size $20.59 \mathrm{~nm}$ (Figure 5 (a) and (b)) revealing that surface of the particle was negatively charged that dispersed in the medi-

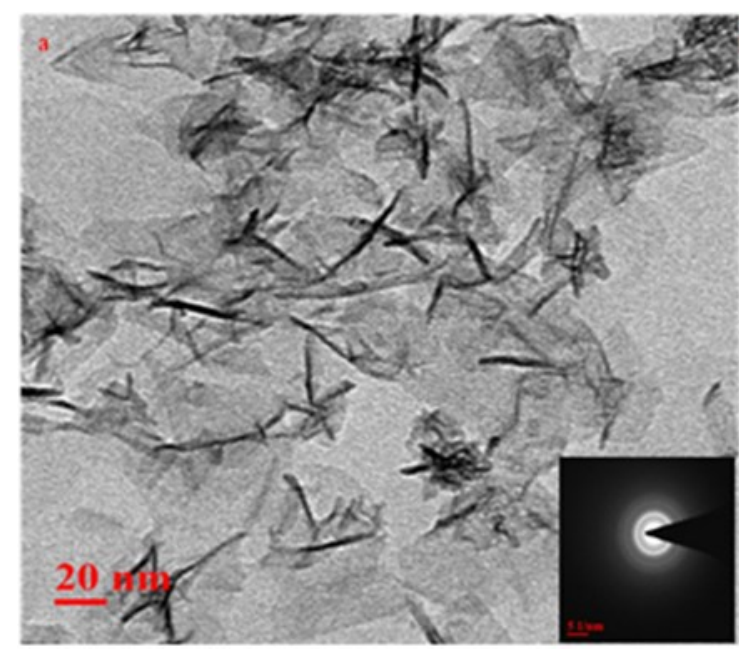

um. To investigate chemical structure of the particles, FT-IR analysis was performed. Two absorption bands located at around 3400 and $1623 \mathrm{~cm}^{-1}$ correspond to $\mathrm{O}-\mathrm{H}$ and $\mathrm{H}-\mathrm{O}-\mathrm{H}$ (Figure 6) [45].

The oxidation state of manganese species in the colloidal solution was also determined iodometrically at $390 \mathrm{~nm}$ based on the previous report [46]. The determined oxidation state of $\mathrm{Mn}$ species in $\mathrm{MnO}_{2}$ was (+4.16), was confirming the formation of $\mathrm{MnO}_{2}$ [47]. The molar extinction coefficient of colloidal $\mathrm{MnO}_{2}$ was found to be $15660 \mathrm{dm}^{3} \cdot \mathrm{mol}^{-1} \cdot \mathrm{cm}^{-1}$ that in a good agreement with previous study [48].

\subsection{Stoichiometry and Product Analysis}

The stoichiometry of the reaction was determined with various ratios of experiments at excess of $\mathrm{MnO}_{2}$ over CIP in acid perchlorate medium at $35^{\circ} \mathrm{C}$ for $12 \mathrm{~h}$ to ensure the completion of the reaction. The excess of $\mathrm{MnO}_{2}$ was esti-

Figure 4. TEM of synthesized colloidal $\mathrm{MnO}_{2}$ at optimum conditions and inset SAED pattern (a); TEM of synthesized colloidal $\mathrm{MnO}_{2}$ at higher $\left[\mathrm{Na}_{2} \mathrm{~S}_{2} \mathrm{O}_{3}\right](\mathrm{b})$.

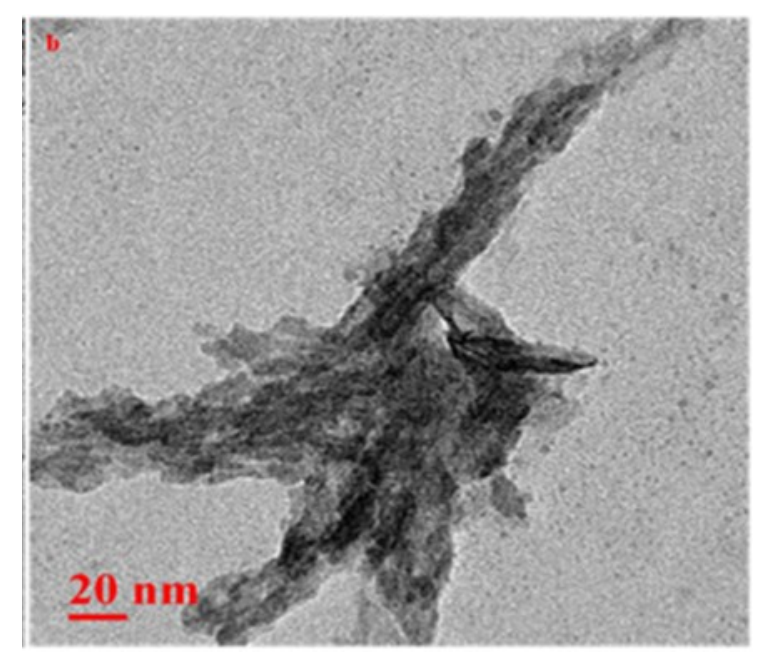

Size Distribution by Intensity

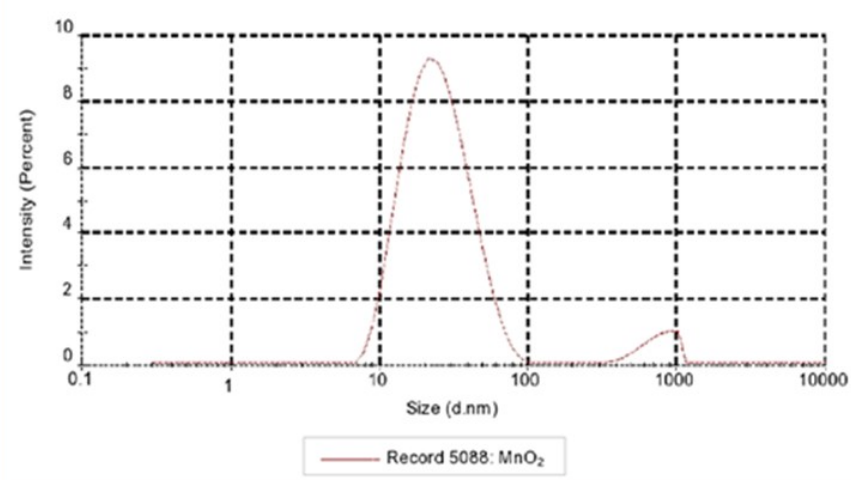

Zeta Potential Distribution

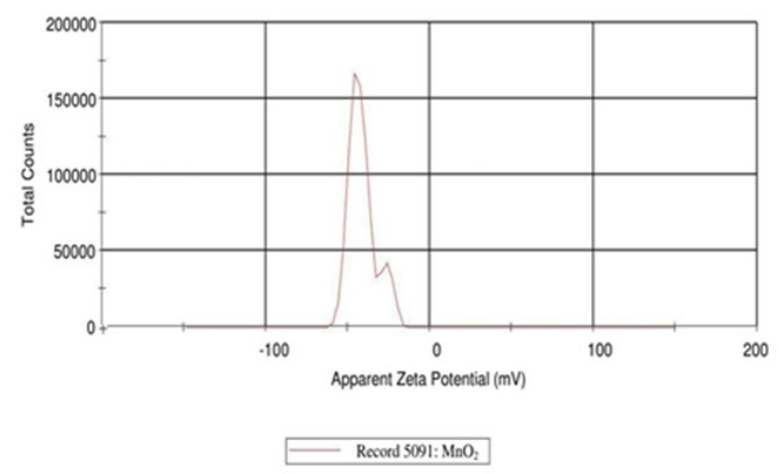

Figure 5. (a) Zeta sizer and (b) Zeta potential of synthesized colloidal $\mathrm{MnO}_{2}$. 


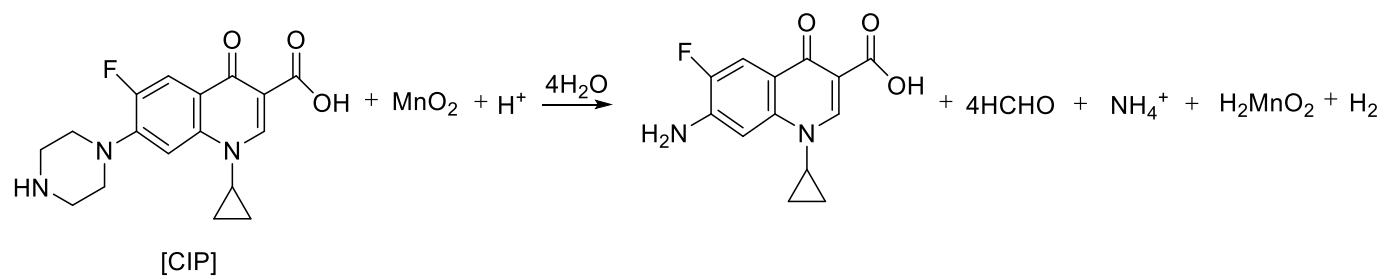

mated spectrophotometrically and the results correspond to the stoichiometry as represented by Equation (1). The product was separated with ether after the completion of the kinetic experiments. The main oxidative product $\{7$ amino-1-cyclopropyl-6-fluoro-1,4-dihydro-4-oxoquinolone-3-carboxylic acid\} was identified with the help of LC-MS and FT-IR analysis.

The major product was confirmed with the molecular ion of $\mathrm{m} / \mathrm{z} 263$ by LC-MS analysis, which corresponds to fully dealkylation of the piperazine ring [49] (Figure 7). It is due to the oxidation of piperazine moiety of CIP between oxidized centers and nitrogen atoms lead to dis-

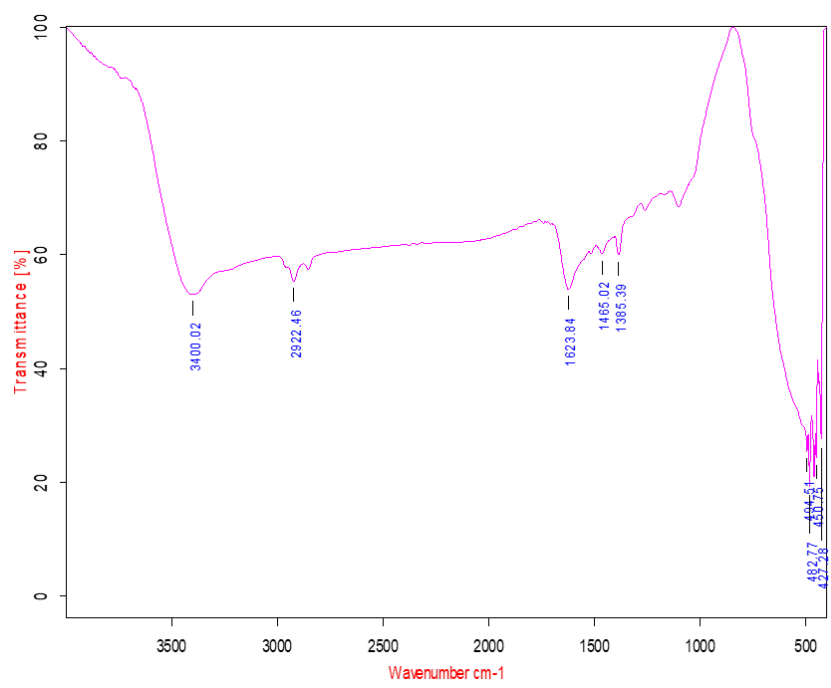

Figure 6. Fourier Transform Infrared spectra of synthesized colloidal $\mathrm{MnO}_{2}$.

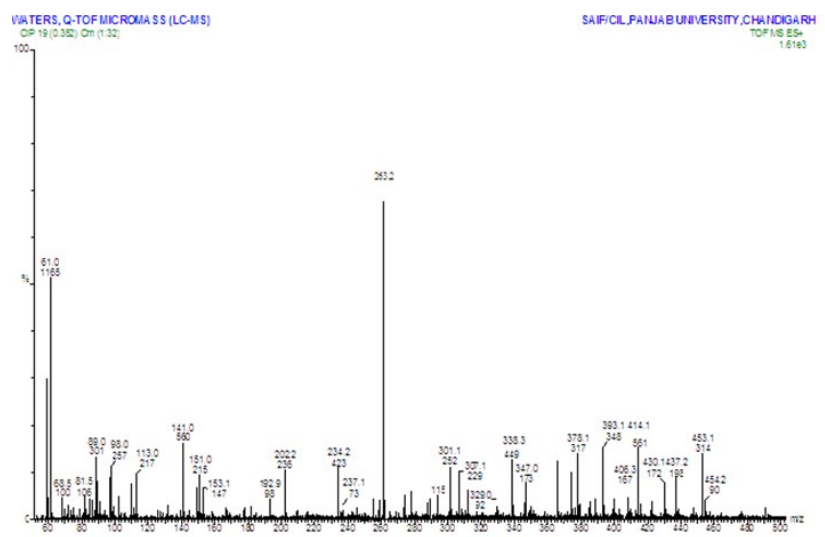

Figure 7. Liquid Chromatography Mass spectra of oxidation product of Ciprofloxacin. tinctive mass loss $\mathrm{m} / \mathrm{z}=69$. This can be ascribed by ring-opening, dealkylation and deamination process and finally yielded 7-amino fluoroquinolone product.

The deamination of CIP was confirmed by FT-IR analysis (Figure 8 ). The spectrum results confirm the $-\mathrm{NH}$ stretching of the $-\mathrm{NH}_{2}$ group at $3375.45 \mathrm{~cm}^{-1}$ and the remaining bands are of the parent compound.

\subsection{Kinetics of CIP Oxidation by Colloidal $\mathrm{MnO}_{2}$}

\subsection{1 $\mathrm{MnO}_{2}$ dependence}

The concentration of $\mathrm{MnO}_{2}$ was varied from $0.75 \times 10^{-5}$ to $7.5 \times 10^{-5} \mathrm{~mol} . \mathrm{dm}^{-3}$ at two different concentrations of CIP $\left(5.0 \times 10^{-4}\right.$ and $\left.8.0 \times 10^{-4}\right)$ but fixed $\left[\mathrm{H}^{+}\right]=2.0 \times 10^{-4}$ mol.dm ${ }^{-3}$ and $\mathrm{I}=$ $4.0 \times 10^{-4}$ mol. $\mathrm{dm}^{-3}$ (adjusted by sodium perchlorate) at $35{ }^{\circ} \mathrm{C}$. Pseudo-first order rate constants $\left(k_{o b s}\right)$ calculated from pseudo first-order plots (Figure 9) $\left(\mathrm{R}^{2}=1.0\right)$ were to be independent of $\mathrm{MnO}_{2}$ concentration (Table 1) indicates reaction is first order concerning to $\mathrm{MnO}_{2}$.

\subsubsection{Ciprofloxacin dependence}

The concentration of CIP was varied from $1.0 \times 10^{-4}$ to $10.0 \times 10^{-4} \mathrm{~mol} . \mathrm{dm}^{-3}$ at a fixed concentration of other reaction ingredients at three temperatures viz. $30{ }^{\circ} \mathrm{C}, 35^{\circ} \mathrm{C}$, and $40{ }^{\circ} \mathrm{C}$. The rate of reaction initially increases and tends towards a limiting value with the higher concentration of the CIP $\left(\mathrm{R}^{2} \leq 0.908\right)$ showing frac-

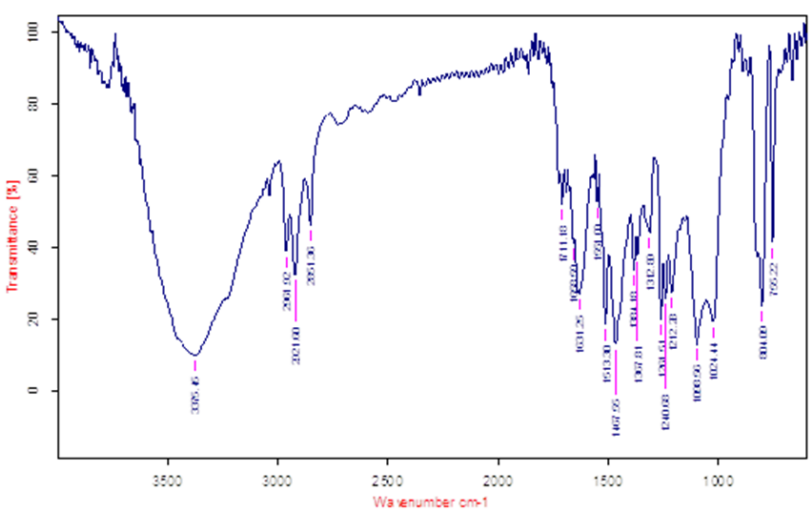

Figure 8. Fourier Transform Infrared spectra of the oxidation product of Ciprofloxacin by $\mathrm{MnO}_{2}$ in aqueous acidic medium. 
Table 1. First order rate constants $\left(k_{o b s}\right)$ for the reaction of ciprofloxacin with $\mathrm{MnO}_{2}$ in aqueous acidic medium at I $=4.0 \times 10^{-4}$ mol. $\mathrm{dm}^{-3}$ and Temperature $=308$ K (S.D. $=$ Standard Deviation)

\begin{tabular}{|c|c|c|c|}
\hline 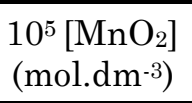 & 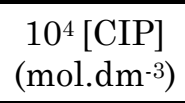 & $\begin{array}{c}10^{4}\left[\mathrm{H}^{+}\right] \\
\left(\mathrm{mol} . \mathrm{dm}^{-3}\right)\end{array}$ & $\begin{array}{c}10^{4} k_{o b s} \pm \text { S.D } \\
\left(\mathrm{s}^{-1}\right)\end{array}$ \\
\hline 0.75 & 5.0 & 2.0 & $8.06 \pm 0.03$ \\
\hline 1.0 & 5.0 & 2.0 & $8.10 \pm 0.04$ \\
\hline 2.0 & 5.0 & 2.0 & $7.98 \pm 0.09$ \\
\hline 3.0 & 5.0 & 2.0 & $8.02 \pm 0.13$ \\
\hline 4.0 & 5.0 & 2.0 & $8.06 \pm 0.19$ \\
\hline 5.0 & 5.0 & 2.0 & $8.00 \pm 0.19$ \\
\hline 6.0 & 5.0 & 2.0 & $7.96 \pm 0.28$ \\
\hline 7.5 & 5.0 & 2.0 & $8.05 \pm 0.35$ \\
\hline 0.75 & 7.5 & 2.0 & $10.52 \pm 0.03$ \\
\hline 1.0 & 7.5 & 2.0 & $11.02 \pm 0.04$ \\
\hline 2.0 & 7.5 & 2.0 & $11.05 \pm 0.08$ \\
\hline 3.0 & 7.5 & 2.0 & $10.95 \pm 0.13$ \\
\hline 4.0 & 7.5 & 2.0 & $11.12 \pm 0.19$ \\
\hline 5.0 & 7.5 & 2.0 & $11.10 \pm 0.19$ \\
\hline 6.0 & 7.5 & 2.0 & $10.94 \pm 0.27$ \\
\hline 7.5 & 7.5 & 2.0 & $11.00 \pm 0.33$ \\
\hline 5.0 & 1.0 & 2.0 & $2.60 \pm 0.03$ \\
\hline 5.0 & 2.0 & 2.0 & $4.52 \pm 0.04$ \\
\hline 5.0 & 3.0 & 2.0 & $5.96 \pm 0.07$ \\
\hline 5.0 & 4.0 & 2.0 & $7.10 \pm 0.08$ \\
\hline 5.0 & 5.0 & 2.0 & $8.00 \pm 0.19$ \\
\hline 5.0 & 6.0 & 2.0 & $8.72 \pm 0.27$ \\
\hline 5.0 & 7.0 & 2.0 & $9.30 \pm 0.33$ \\
\hline 5.0 & 8.0 & 2.0 & $9.64 \pm 0.38$ \\
\hline 5.0 & 9.0 & 2.0 & $9.81 \pm 0.42$ \\
\hline 5.0 & 10.0 & 2.0 & $9.92 \pm 0.47$ \\
\hline 5.0 & 5.0 & 1.0 & $4.02 \pm 0.03$ \\
\hline 5.0 & 5.0 & 1.5 & $5.96 \pm 0.06$ \\
\hline 5.0 & 5.0 & 2.0 & $8.00 \pm 0.08$ \\
\hline 5.0 & 5.0 & 2.5 & $10.02 \pm 0.13$ \\
\hline 5.0 & 5.0 & 3.0 & $12.10 \pm 0.17$ \\
\hline 5.0 & 5.0 & 3.5 & $14.04 \pm 0.19$ \\
\hline 5.0 & 5.0 & 4.0 & $15.98 \pm 0.27$ \\
\hline
\end{tabular}


tional order dependence concerning to CIP (Table 1).

\subsubsection{Hydrogen ion dependence}

Hydrogen ion concentration was varied from $1.0 \times 10^{-4}$ to $4.0 \times 10^{-4} \mathrm{~mol} . \mathrm{dm}^{-3}$ employing perchloric acid at a fixed concentration of other reactants and conditions. The rate of reaction increases with increasing concentration of $\mathrm{H}^{+}\left(\mathrm{R}^{2}\right.$ $=1.0$ ) showing first-order reaction concerning to $\mathrm{H}^{+}$concentration (Table 1).

\subsubsection{Ionic strength dependence}

Ionic strength was varied from $2.0 \times 10^{-4}$ to $10.0 \times 10^{-4}$ mol.dm ${ }^{-3}$ employing sodium perchlorate keeping constant concentration of other reactants and conditions. However, the rate of reaction remains unaffected by the change in ionic strength (Table 1). The negligible effect of ionic strength on the rate of reaction suggests that the reaction is either between two neutral species or a neutral and a charged species [50].

\subsubsection{Test for free radical}

The possible intervention of free radicals during the oxidation reactions was examined by a polymerization test. Known amounts of acrylonitrile scavenger are added to reaction mixtures, which are kept for $6 \mathrm{~h}$ in an inert atmosphere. On dilution of the mixtures with methanol, white precipitates are formed, thus confirming the presence of free radicals intervention in these reactions. The blank experiment

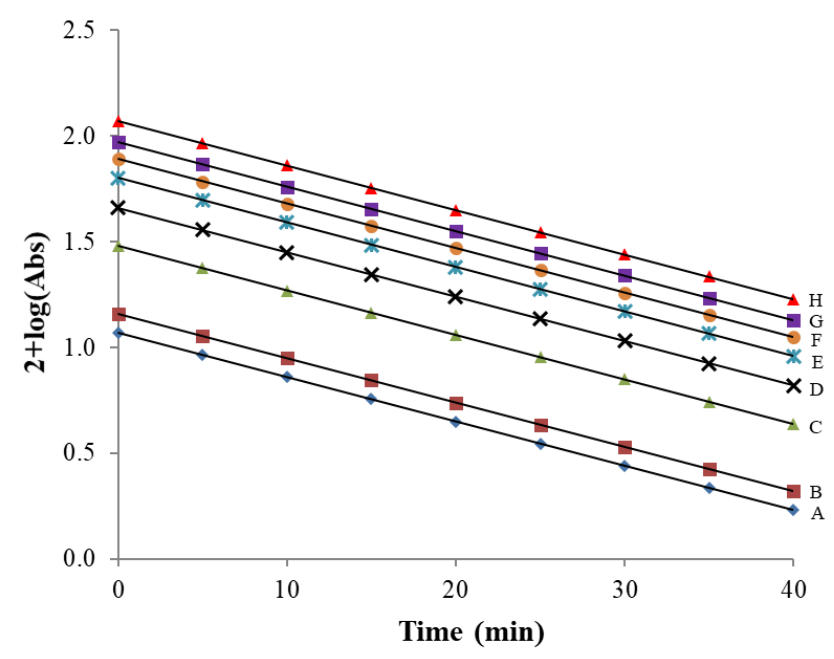

Figure 9. Variation of $\mathrm{MnO}_{2}$ by the plots of log Absorbance versus Time. $[\mathrm{CIP}]=5.0 \times 10^{-4},\left[\mathrm{H}^{+}\right]=$ $2.0 \times 10^{-4}, \mathrm{I}=4.0 \times 10^{-4}$ and $105\left[\mathrm{MnO}_{2}\right]=(\mathrm{A}) 0.75$; (B) 1.0 ; (C) 2.0; (D) 3.0; (E) 4.0; (F) 5.0 (G) 6.0; (H) $7.5 / \mathrm{mol}^{-\mathrm{dm}^{-3}}$. of reacting $\mathrm{MnO}_{2}$ and CIP alone with acrylonitrile did not induce polymeric species under the same conditions. This indicates that the reactions proceeded via free radical pathways.

\subsection{Mechanism}

According to Scheme 1 ciprofloxacin reacts with $\mathrm{MnO}_{2}$ and complex is obtained in first equilibrium step. Further complex combines with $\mathrm{H}^{+}$to give free radical in the rate determining step. This free radical again reacts with $\mathrm{HMnO}_{2}$ to give final products. The rate being first-order dependence of $\mathrm{H}^{+}$ion concentration, a reaction mechanism consisting of Scheme (1) can be proposed (Equations (2-4).

The proposed mechanism leads to the rate law (5) and (6).

$$
\begin{aligned}
& -\frac{d[M n(I V)}{d t}=\frac{k K[M n(I V)][C I P]\left[H^{+}\right]}{1+K[C I P]} \\
& k_{\text {obs }}=\frac{k K[C I P]\left[H^{+}\right]}{1+K[C I P]}
\end{aligned}
$$

The double reciprocal plot between $\left(k_{o b s}\right)^{-1}$ and $[\mathrm{CIP}]^{-1}$ was made from Equation (6) that yield a straight line with non-zero intercept $\left(\mathrm{R}^{2}=\right.$ 0.999) (Figure 10). The value of ' $k$ ' to be $1.40 \times 10^{-3}, 1.90 \times 10^{-3}, 2.44 \times 10^{-3} / \mathrm{s}^{-1}$ from intercepts and value of ' $K$ ' to be $10.5 \times 10^{2}, 15.2 \times 10^{2}$, $20.7 \times 10^{2} / \mathrm{dm}^{3} \cdot \mathrm{mol}^{-1}$ from the ratio of intercept<smiles>O=C(O)c1cn(C2CC2)c2ccc(F)cc2c1=O</smiles>

Scheme 1. Proposed mechanism for the oxidation of CIP by $\mathrm{MnO}_{2}$.

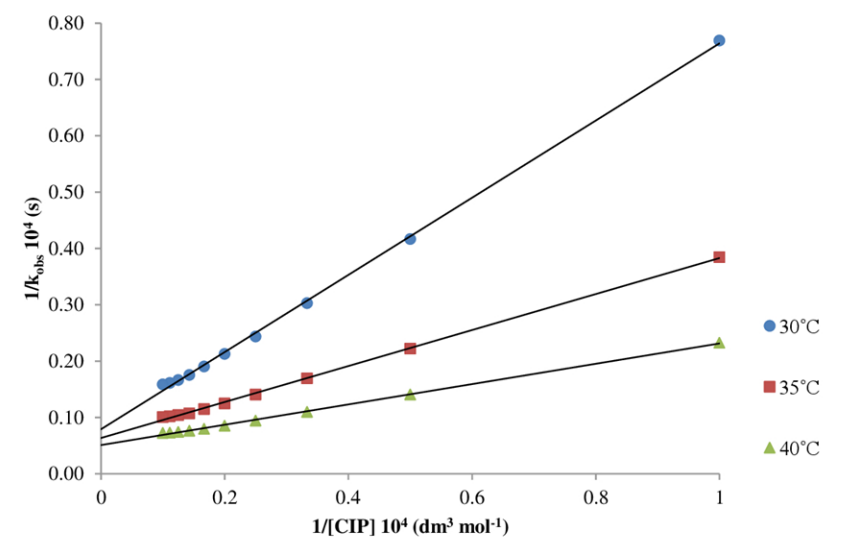

Figure 10. Plot of $1 / \mathrm{k}_{\text {obs }}$ verses $1 /[\mathrm{CIP}]$ at three temperatures. $\left[\mathrm{MnO}_{2}\right]=5.0 \times 10^{-5},\left[\mathrm{H}^{+}\right]=2.0 \times 10^{-4}$

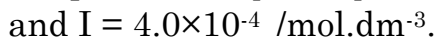



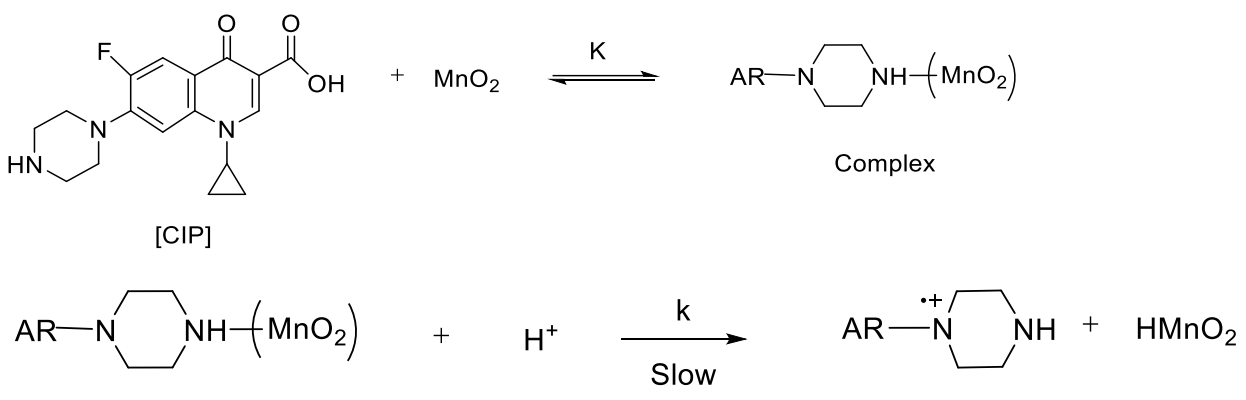

Complex

Free radical

$$
\mathrm{AR} \stackrel{\cdot+}{\mathrm{NH}}+\mathrm{HMnO}_{2} \underset{4 \mathrm{H}_{2} \mathrm{O}}{\stackrel{\text { Fast step }}{\longrightarrow}} \mathrm{AR}-\mathrm{NH}_{2}+4 \mathrm{HCHO}+\mathrm{NH}_{4}^{+}+\mathrm{H}_{2} \mathrm{MnO}_{2}+\mathrm{H}_{2}
$$

Free radical

and slope at $30^{\circ} \mathrm{C}, 35^{\circ} \mathrm{C}$, and $40^{\circ} \mathrm{C}$ respectively were calculated at $\mathrm{I}=4.0 \times 10^{-4} \mathrm{~mol} . \mathrm{dm}^{-3}$. The enthalpy and energy of activation for the ratedetermining step were calculated to be 32.48 kJ.mol-1 and $35.04 \mathrm{~kJ} . \mathrm{mol}^{-1}$ at $35^{\circ} \mathrm{C}$ respectively. The values are closer to earlier study [51]. The value of entropy of activation $(\Delta S)=-92.27$ $\mathrm{JK}^{-1} \mathrm{~mol}^{-1}$ express the formation of intermediate complex and such an activated complex is more ordered than the reactants due to loss of degree of freedom. The value of $\Delta \mathrm{G}=92.06 \mathrm{~kJ} . \mathrm{mol}^{-1}$ suggests enhanced formation of the intermediate with raising temperature as well as nonspontaneous complex formation.

\section{Conclusion}

The present study reports highly stable needle-shaped colloidal nano-sized $\mathrm{MnO}_{2}$ was formed by simple laboratory equipment in ambient condition. The characterization results reveal that formed colloidal $\mathrm{MnO}_{2}$ were needle shape with an average size $20.59 \mathrm{~nm}$ and crystalline in nature. A kinetic and mechanistic study of CIP oxidation by formed colloidal $\mathrm{MnO}_{2}$ has been first time investigated in aqueous acidic medium. The reaction follows firstorder kinetics concerning to $\mathrm{MnO}_{2}$ and $\mathrm{H}^{+}$ion under first-order reaction conditions. Results and mechanism indicate that $\mathrm{HMnO}_{2}$ is reactive species of $\mathrm{MnO}_{2}$. Since dealkylated products are obtained in the present study, it is evident that the products of the title reaction have an antimicrobial activity after oxidation. Thus the degradation of fluoroquinolones plays an important role in the field of wastewater treatment. The kinetic results have also been used to evaluate various activation parameters associated with the degradation of CIP by $\mathrm{MnO}_{2}$ in aqueous acidic medium.

\section{Acknowledgments}

We are grateful to the Department of Science and Technology sponsored FIST laboratory of our institution for experimental work and Sophisticated Analytical Instrumentation Facility, CIL, Punjab University, Chandigarh for LC-MS measurements.

\section{References}

[1] Fatiadi, A.J. (1986). The oxidation of organic compounds by active manganese dioxide. Org. Synth. Oxd. Met. Compd. 119-260.

[2] Khan, Z., Raju, R., Mohd, A., Kabir-Ud-Din, K. (2004). Oxidation of lactic acid by water soluble (colloidal) manganese dioxide. Int. J. Chem. Kinet., 36, 359-366.

[3] Zhang, H., Chen, W.R., Huang, H.C. (2008). Kinetic modeling of oxidation of antibacterial agents by manganese oxide. Environ Sci Technol, 42: 5548-5554.

[4] Sharma, T.C., Lal, A., Saksena, V. (1976). Oxidation of flavanone hydrazones with manganese dioxide. Bull. Chem. Soc. Jpn., 49, 28812882 .

[5] Basak, B., Malati, M.A. (1977). Characterisation of manganese dioxides-IV. The oxidation of chromium(III) ions by manganese dioxides. J. Inorg. Nucl. Chem. 39, 1081-1084.

[6] Kienzle, F. (1983). A facile synthesis of 1, 4dihydro-1- alkyl-2H-3,1-benzoxazines and related compounds. Tetrahedron Lett., 24, 22132216.

[7] Mata-Perez, F., Perez-Benito, J.F. (1985). Identification of the product from the reduction of permanganate ion by trimethylamine in aqueous phosphate buffers. Can. J. Chem., 63, 988-992. 
[8] Perez-Benito, J.F., Arias, C. (1992). A kinetic study of the reaction between soluble (colloidal) manganese dioxide and formic acid. J. Colloid Interface Sci., 149, 92-97.

[9] Perez-Benito, J.F., Ariasm C., Amat, E. (1996).A kinetic study of the reduction of colloidal manganese dioxide by oxalic acid. $J$. Colloid Interface Sci., 177, 228-297.

[10] Perez-Benito, J.F., Brillas, E., Pouplana, R. (1989). Identification of a soluble form of colloidal manganese (IV). Inorg. Chem., 28, 390392.

[11] Altaf, M., Jaganyi, D. (2014). Kinetics of the degradation of l-cysteine at freshly prepared nano-sized $\mathrm{MnO}_{2}$ surfaces in the absence and presence of TX-100. J. Solution Chem., 43, 269-282.

[12] Khan, Z., Raju, Akram, M., Kabir-Ud-Din, K. (2004). Oxidation of lactic acid by water soluble (colloidal) manganese dioxide. Int. J. Chem. Kinet., 36, 359-366.

[13] Saeed, M., Ilyas, M., Siddique, M., Ahmad, A. (2013). Oxidative degradation of oxalic acid in aqueous medium using manganese oxide as catalyst at ambient temperature and pressure. Arab. J. Sci. Eng., 38, 1739-1748.

[14] Freeman, F., Chang, L.Y., Kappos, J.C., Sumarta, L. (1987). Permanganate ion oxidations. 18. Kinetics and mechanism of the oxidation of (E)- 3-(2-pyridinyl)-, (E)-3-(3pyridinyl)-and (E)-3-(4-pyridinyl)-2- propenoates. J. Organo Met. Chem., 52, 1460-1464.

[15] Kabir-ud-Din, K., Altaf, M., Akram, M. (2008). The kinetics of oxidation of Ltryptophan by water-soluble colloidal manganese dioxide. J. Dispers. Sci. Technol., 29, 809-816.

[16] Mata-Perez, F., Perez-Benito, J.F. (1986). $\mathrm{Mn}(\mathrm{IV})$ Stabilized in Solution by Phosphate Ions. A Spectrophotometric Evidence of its Colloidal Nature. J. Phys. Chem. Leipzig, 267, 120-124.

[17] Qamruzzaman, Q., Nasar, A. (2014). Degradation of tricyclazole by colloidal manganese dioxide in the absence and presence of surfactants. J. Ind. Eng. Chem., 20, 897-902.

[18] Klausen, J., Haderlein, S.B., Schwarzenbach, R.P. (1997). Oxidation of substituted anilines by aqueous $\mathrm{MnO}_{2}$ : effect of co-solutes on initial and quasi-steady-state kinetics. Environ. Sci. Technol., 31, 2642-2649.

[19] McArdell, C.S., Stone, A.T., Tian, J. (1998). Reaction of EDTA and related aminocarboxylate chelating agents with $\mathrm{CoIIIOOH}$ (heterogenite) and MnIIIOOH (manganite). Environ. Sci. Technol., 32, 2923-2930.
[20] Wang, D., Shin, J.Y., Cheney, M.A., SpositoGand Spiro, T.G. (1999). Manganese dioxide as a catalyst for oxygen-independent atrazine dealkylation. Environ. Sci. Technol., 33, 3160-3165.

[21] Li, F., Liu, C., Liang, C., Li, X., Zhang, L. (2008). The oxidative degradation of 2mercaptobenzothiazole at the interface of $b$ $\mathrm{MnO}_{2}$ and water. J. Hazard. Mater., 154, 1098-1105.

[22] Li, H., Lee, L.S., Schulze, D.G., Guest, C.A. (2003). Role of soil manganese in the oxidation of aromatic amines. Environ. Sci. Technol. 37, 2686-2693.

[23] Ukrainczyk, L., McBride, M.B. (1993). Oxidation and dechlorination of chlorophenols in dilute aqueous suspensions of manganese oxides: reaction products. Environ. Toxicol. Chem. 12, 2015-2022.

[24] Akram, M., Altaf, M., Kabir-ud-din, K. (2007). Oxidation of aspartic acid by water soluble colloidal $\mathrm{MnO} 2$ in absences and presence of ionic and nonionic surfactants. Indian $J$. Chem., 46, 1427-1431.

[25] Kabir-Ud-Din, K., Fatma, W., Khan, Z. (2004). Effect of surfactants on the oxidation of oxalic acid by soluble colloidal $\mathrm{MnO}_{2}$ Colloids and Surfaces A: Physicochemical and Engineering Aspects, 234, 159-164.

[26] Kabir-Ud-Din, K., Iqubal, S.M.S. (2010). Kinetics of the reduction of water soluble colloidal $\mathrm{MnO}_{2}$ by mandelic acid in the absence and presence of non-ionic surfactant Triton X100. Colloid Journal, 72, 195-204.

[27] Khan, Z., Kumar, P., Kabir-Ud-Din, K. (2004). Kinetics and mechanism of the reduction of colloidal manganese dioxide by Dfructose. Colloids and Surfaces A: Physicochemical and Engineering Aspects, 248, 2531.

[28] Kabir-Ud-Din, K., Zaidi, N.H., Akram, M., Khan, Z. (2006). Mechanism of the oxidation of $\mathrm{D}$-glucose onto colloidal $\mathrm{MnO}_{2}$ surface in the absence and presence of TX-100 micelles. Colloid and Polymer Science, 284, 387-1393.

[29] Herszage, J., Afonso, M.D.S., Luther, G. (2003). Oxidation of cysteine and glutathione by soluble polymeric $\mathrm{MnO}_{2}$. Environ. Sci. Technol., 37, 3332-3338.

[30] Diab, N., Abu-Shqair, I., Al-Subu, M., Salim, R. (2013). Kinetics of Oxidation of Some Fluoroquinolones by Hexacyanoferrate (III) in Alkaline Medium. International Journal of Chemistry, 34, 1388-1394.

[31] Tazwar, G., Jain, A., Mittal, N., Devra, V. (2017). Oxidation of ciprofloxacin by hexacyanoferrate(III) in the presence of $\mathrm{Cu}(\mathrm{II})$ as a 
catalyst: A kinetic study. Int. J. Chem. Kinet., 49(7), 534-542.

[32] Wang, P., Yi-Liang, H., Ching-Hua, C.H. (2010). Oxidation of fluoroquinolone antibiotics and structurally related amines by chlorine dioxide: Reaction kinetics, product and pathway evaluation. Water Res., 44, 59895998.

[33] Yang, B., Kookana, R.S., Williams, M., Ying, G.G., Du, J., Doan, H., Kumar, A. (2016). Oxidation of ciprofloxacin and enrofloxacin by ferrate(VI): Products identification, and toxicity evaluation. J. Hazard. Mater., 320, 296303.

[34] Zhou, Z., Jiang, J-Q. (2015). Reaction kinetics and oxidation products formation in the degradation of ciprofloxacin and ibuprofen by ferrate(VI). Chemosphere, 119, S95-S100.

[35] Zhang, H., Huang, C.H. (2005). Reactivity and transformation of antibacterial N-oxides in the presence of manganese oxide. Environ. Sci. Technol., 39, 593-601.

[36] Thabaj, K.A., Kulkarni, S.D., Chimatadar, S.A., Nandibewoor, S.T. (2007). Oxidative transformation of ciprofloxacin by alkaline permanganate - A kinetic and mechanistic study. Polyhydrone, 26, 4877-4885.

[37] Xiao, X., Sun, S-P., McBride, M.B., Lemley, A.T. (2013). Degradation of ciprofloxacin by cryptomelane-type manganese(III/IV) oxides. Environ. Sci. Pollut. Res., 20, 10-21.

[38] Hu, L., Martin, H.M., Stratlumann, T.J. (2010). Oxidation of antibiotics during water treatment with potassium permanganate. Environ. Sci. Technol., 44, 6416-6422.

[39] Hu, L., Stemig, A.M., Wammer, K.H., Strathmann, T.J. (2011). Oxidation of antibiotics during water treatment with potassium permanganate: reaction pathways and deactivation. Environ. Sci. Technol., 45, 3635-3642.

[40] Chen, G., Zhao, L., Dong, Y.H. (2011). Oxidative degradation kinetics and products of chlortetracycline by manganese dioxide. $J$. Hazard. Mater., 193, 128-138.

[41] Singh, A.K., Sen, N., Chatterjee, S.K. (2016). Oxidative degradation of norfloxacin by water soluble colloidal $\mathrm{MnO}_{2}$ in the presence of cationic surfactant. Indian J of Chem, 55A: 10591067.
[42] Tazwar, G., Jain, A., Devra, V. (2017). Oxidative degradation of levofloxacin by watersoluble manganese dioxide in aqueous acidic medium: a kinetic study. Chem. Pap. 71, 1749-1758. doi:10.1007/s11696-017-0167-y

[43] Li, Y., Wei, D., Du, Y. (2015). Oxidative transformation of levofloxacin by $\mathrm{MnO}_{2}$ : Products, pathways and toxicity assessment. Chemosphere, 119, 282-288.

[44] Zhang, H.C., Haung, C.H. (2003). Oxidative transformation of triclosan and chlorophene by manganese oxide. Environ. Sci. Technol., 37, 2421-2430.

[45] Huang, Y., Lin, Y., Li, W. (2013). Controllable syntheses of a- and $\delta-\mathrm{MnO}_{2}$ as cathode catalysts for zinc-air battery. Electrochim. Acta, 99, 161-165.

[46] Islam, M.A., Rahman, M.M. (2013). Soluble colloidal manganese dioxide: formation, identification and prospects of application. Colloidal Journal, 75, 591-595.

[47] Islam, M.M., Rahman, M.M. (2015). Dissolution kinetics of colloidal manganese dioxide in aqueous hydrochloric acid at $298 \mathrm{k}$. Russian Journal of Physical Chemistry A, 89, 706-709.

[48] Akram, M., Altaf, M., Kabir-Ud-Din, K. (2011). Oxidative degradation of dipeptide (glycyl-glycine) by water soluble colloidal manganese dioxide in the aqueous and micellar media. Colloids Surf. B, 82, 217-223.

[49] Zhang, H.C., Haung, C.H. (2005). Oxidative transformation of Fluoroquinolone antibacterial agents and structurally related amines by manganese oxide. Environ. Sci. Technol., 39, 4474-4483. doi: 10.1021/es048166d

[50] Laidler, K.J. (2004). Chemical Kinetics. Pearson Education, (Singapore) Pte. Ltd, Indian Branch, Delhi, India, $3^{\text {rd }}$ edn.

[51] Jain, A., Jain, S., Devra, V. (2015). Kinetics and mechanism of permanganate oxidation of ciprofloxacin in aqueous sulphuric acid medium. International Journal of Pharmaceutical Sciences and Drug Research, 7, 205-210. 